\title{
Hormonal Control of Substrate Cycling in Humans
}

\author{
Hiroshi Miyoshi, Gerald I. Shulman, * Edward J. Peters, Marta H. Wolfe, Dariush Elahi, ${ }^{\ddagger}$ and Robert R. Wolfe \\ The Shriners Burns Institute and The University of Texas Medical Branch, Galveston, Texas 77550; *Department of Molecular \\ Biophysics \& Biochemistry, Yale Medical School, New Haven, Connecticut 06520; ${ }^{\ddagger}$ Beth Israel Hospital and ${ }^{\ddagger}$ Harvard Medical School, \\ Boston, Massachusetts 02138
}

\begin{abstract}
Recent studies have established the existence of substrate cycles in humans, but factors regulating the rate of cycling have not been identified. We have therefore investigated the acute response of glucose/glucose-6P-glucose (glucose) and triglyceride/fatty acid (TG/FA) substrate cycling to the infusion of epinephrine $(0.03 \mu \mathrm{g} / \mathrm{kg} \cdot \mathrm{min})$ and glucagon. The response to a high dose glucagon infusion $(2 \mu \mathrm{g} / \mathrm{kg} \cdot \mathrm{min})$ was tested, as well as the response to a low dose infusion (5 $\mathrm{ng} / \mathrm{kg} \cdot \mathrm{min}$ ), with and without the simultaneous infusion of somatostatin $(0.1 \mu \mathrm{g} / \mathrm{kg} \cdot \mathrm{min})$ and insulin $(0.1 \mathrm{mU} / \mathrm{kg} \cdot \mathrm{min})$. Additionally, the response to chronic prednisone $(50 \mathrm{mg} / \mathrm{d})$ was evaluated, both alone and during glucagon (low dose) and epinephrine infusion. Finally, the response to hyperglycemia, with insulin and glucagon held constant by somatostatin infusion and constant replacement of glucagon and insulin at basal rates, was investigated. Glucose cycling was calculated as the difference between the rate of appearance $\left(R_{\mathbf{a}}\right)$ of glucose as determined using $2-d_{1}-$ and $6,6-d_{2}$-glucose as tracers. TG/FA cycling was calculated by first determining the $R_{\mathrm{a}}$ glycerol with d5-glycerol and the $R_{\mathrm{a}}$ FFA with $\left[1-{ }^{13} \mathrm{C}\right]$ palmitate, then subtracting $\boldsymbol{R}_{\mathrm{a}}$ FFA from three times $\boldsymbol{R}_{\mathrm{a}}$ glycerol.

The results indicate that glucagon stimulates glucose cycling, and this stimulatory effect is augmented when the insulin response to glucagon infusion is blocked. Glucagon had minimal effect on TG/FA cycling. In contrast, epinephrine stimulated TG/FA cycling, but affected glucose cycling minimally. Prednisone had no direct effect on either glucose or TG/FA cycling, but blunted the stimulatory effect of glucagon on glucose cycling. Hyperglycemia, per se, had no direct effect on glucose or TG/FA cycling. Calculations revealed that stimulation of TG/FA cycling theoretically amplified the sensitivity of control of fatty acid flux, but no such amplification was evident as a result of the stimulation of glucose cycling by glucagon.
\end{abstract}

\section{Introduction}

Substrate cycles exist when opposing, nonequilibrium reactions, catalyzed by different enzymes, are active simultaneously. The net result of substrate cycling is thermogenesis, and amplification of enzymatic control can also occur (1). During the past ten years, a number of studies have investi-

Address correspondence to Dr. Wolfe, Shriners Burns Institute, 610 Texas Ave., Galveston, TX 77550.

Received for publication 16 July 1987 and in revised form $30 \mathrm{No}$ vember 1987

J. Clin. Invest.

(c) The American Society for Clinical Investigation, Inc.

$0021-9738 / 88 / 05 / 1545 / 11 \quad \$ 2.00$

Volume 81, May 1988, 1545-1555 gated the regulation of substrate cycles in in vitro systems or in animal studies (e.g., references 2 to 7). More recently, studies of glucose and fructose cycling in human subjects have been undertaken by ourselves $(8,9)$ and others $(10-14)$. We have also investigated triglyceride/fatty acid (TG/FA) ${ }^{1}$ cycling in humans (15). This involves the processes of lipolysis and reesterification occurring simultaneously.

In our study of glucose and TG/FA cycling in severely burned patients, we found that both cycles were increased three- to fivefold above normal (9). Since glucagon was markedly elevated in these burned patients, and the extent of the hypermetabolic response in burn patients has recently been found to be directly related to the glucagon concentration (16), it was logical to suspect glucagon as the mediator of the increased glucose cycling. However, the role of glucagon in controlling the rate of substrate cycling in humans is not clear. In vitro experiments have generally indicated that glucagon inhibits cycling (3), but Issekutz concluded that glucagon stimulated hepatic glucose cycling in the conscious dog (6). It is also possible that glucagon contributes to increased TG/FA cycling in vivo. In vitro experiments have documented that glucagon stimulates lipolysis $(17,18)$. Coupled with an increased reesterification of FFA due to secondary hyperglycemia (15), it is possible that an elevation in glucagon could increase TG/FA cycling. However, in vivo experiments have not determined the effect of glucagon on the rates of release of glycerol (as an index of lipolysis) or of FFA.

The action of other hormones on substrate cycling in humans is also unclear. Whereas beta blockade with propranolol in severely burned patients decreased TG/FA cycling and did not affect glucose cycling (7), it is not known how either cycle is affected by epinephrine infusion. Issekutz (6) reported that cortisol had a direct stimulatory effect on glucose cycling in the dog, and that cortisol amplified the stimulatory effect of glucagon. Similar studies have not been performed in humans, nor has any in vivo assessment of the effect of cortisol on TG/FA cycling.

To better understand the roles of glucagon, epinephrine, and cortisol in the regulation of glucose and TG/FA cycling in humans, we have performed a series of experiments using stable isotopic tracers to quantify the rates of cycling. The response to glucagon and epinephrine infusion has been evaluated before and after several days of treatment with prednisone. In addition, the response to glucagon has been evaluated in the setting of a constant insulin concentration (by virtue of inhibition of secretion with somatostatin and replacement at a constant basal rate), and the role of hyperglycemia, per se, has been tested by infusing unlabeled glucose while holding both glucagon and insulin constant with somatostatin and appropriate hormonal replacement.

1. Abbreviations used in this paper: GEMS, gas chromatograph mass spectrometer; m/e, mass/charge ratio; TG/FA, triglyceride/fatty acid. 


\section{Methods}

Studies were performed in normal volunteers ranging in age from 20 to $32(\bar{x}=24 \pm 1)$ yr. They were given a complete physical examination and considered to be in good health, and they had no history of any metabolic disease or prolonged medication. They were all in the normal range of weight for height. The average height and weight was $70 \pm 2 \mathrm{in}$. and $71.8 \pm 2 \mathrm{~kg}$. The protocol was approved by the Institutional Review Board of The University of Texas Medical Branch, and informed consent was obtained from each volunteer.

All volunteers were admitted to the Clinical Research Center of the above institution the day before the study. They were given a standard hospital meal in the evening, and the study was performed the following morning after 14 to $16 \mathrm{~h}$ of fasting. Teflon catheters were placed into the antecubital vein of one arm for infusions and into a contralateral dorsal hand vein for arterialized venous sampling, using the heated-hand technique (19).

After the baseline blood sample, a constant infusion of 2- $d_{1}$-glucose and 6,6- $d_{2}$-glucose (Cambridge Isotope Laboratories, Woburn, MA), d5-glycerol (Merck Isotopes, Montreal, Canada) and $\left[1-{ }^{13} \mathrm{C}\right]$ palmitate (Tracer Technology, Newton, MA) were given. A stock solution of glucose isotope was made in sterile water. For infusion, the appropriate amount of concentrated stock solution was diluted in $0.9 \%$ saline. The palmitate was bound to 5\% human albumin (Cutter Biological, Alameda, CA), as described previously (20), and the glycerol was added directly to the albumin-palmitate mixture. All isotope solutions were infused by means of calibrated syringe pumps (Harvard Apparatus Co., Inc., Natick, MA). The glucose isotopes were infused through catheters with $0.22-\mu \mathrm{m}$ filters in the line (Bard, North Reading, MA); this was not possible with the palmitate mixture, due to the albumin not easily passing through the filter. Both the potassium salt of palmitate (dissolved in water) and $d 5$-glycerol were passed through a $0.22-\mu \mathrm{m}$ filter when injected into the bottle containing the sterile albumin solution.

The approximate infusion rates were as follows: $2-d_{1-}$ and $6,6-d_{2-}$ glucose, $0.22 \mu \mathrm{mol} / \mathrm{kg} \cdot \mathrm{min} ; d 5$-glycerol, $0.1 \mu \mathrm{mol} / \mathrm{kg} \cdot \mathrm{min}$; and $\left[1-{ }^{13} \mathrm{C}\right]$ palmitate, $0.04 \mu \mathrm{mol} / \mathrm{kg} \cdot \mathrm{min}$. In each experiment the exact infusion rate was determined by measuring the concentration of isotope in the infusion mixture and multiplying that value by the infusion rate of the solution (milliliters per minute). At the start of the constant infusions, priming doses of $2-d_{1}$ - and $6,6-d_{2}$-glucose were given (17.8 $\mu \mathrm{mol} / \mathrm{kg}$ ). Glycerol and palmitate primes were not needed.

\section{Experimental protocols}

Glucagon experiments. In two protocols ( $n=4$ in each), the first 90 min involved only the infusion of the glucose, glycerol, and palmitate tracers. Then, without interruption of the isotope, glucagon was infused for the next $60 \mathrm{~min}$. Two rates of glucagon were used; in one case, the glucagon infusion rate $(2 \mu \mathrm{g} / \mathrm{kg} \cdot \mathrm{min})$ was high enough to elicit the maximum response to glucagon. The other infusion rate $(5$ $\mathrm{ng} / \mathrm{kg} \cdot \mathrm{min}$ ) was designed to test the response to an elevated glucagon concentration in the physiological range.

In the third group of studies the acute response to glucagon $(n=4)$ was evaluated while endogenous insulin release was blocked. Before the start of the isotope infusion, somatostatin (Serono, Inc., Denens, Switzerland) was infused at the rate of $0.1 \mu \mathrm{g} / \mathrm{kg} \cdot \mathrm{min}$ in order to inhibit endogenous insulin and glucagon secretion. Basal replacement of insulin $(0.1 \mathrm{mU} / \mathrm{kg} \cdot \mathrm{min})$ and glucagon $(1 \mathrm{ng} / \mathrm{kg} \cdot \mathrm{min})$ was then accomplished by infusion. For $\sim 1-1.5 \mathrm{~h}$, the exact replacement rate of insulin was adjusted slightly so that a stable, normal blood glucose concentration could be achieved. After that was accomplished no further change was made in the basal replacement rates. The isotope infusions described above were then started. After $90 \mathrm{~min}$ the glucagon infusion rate was increased from 1 to $6 \mathrm{ng} / \mathrm{kg} \cdot \min$ and maintained at that rate for the next $60 \mathrm{~min}$. Thus, the increase in glucagon infusion rate (above basal) was $5 \mathrm{ng} / \mathrm{kg} \cdot \mathrm{min}$, which was the same infusion rate as in the protocol without somatostatin (described above).
Epinephrine experiments. In six subjects the response to a low dose epinephrine infusion was examined. After the initial basal period, in which only tracers $\left(2-d_{1}, 6,6-d_{2}\right.$-glucose, $d 5$-glycerol, and $\left[1-{ }^{13} \mathrm{C}\right] \mathrm{pal}$ mitate) were infused, epinephrine was given as a constant infusion at the rate of $0.03 \mu \mathrm{g} / \mathrm{kg} \cdot \mathrm{min}$ for $60 \mathrm{~min}$. This rate was selected because Clutter et al. (21) had previously shown that this rate of epinephrine infusion was adequate to stimulate both glucose production and lipolysis, yet the resulting plasma concentration of epinephrine $(\sim 400$ $\mathrm{pg} / \mathrm{ml}$ ) is in the same range as that observed in severely stressed patients (such as burned patients) (9).

Prednisone experiments. The response to prednisone treatment was assessed in six subjects. All had participated in the epinephrine study, as described above, and four also participated in the low dose glucagon study. After the initial studies, they received $50 \mathrm{mg}$ prednisone a day for $4 \mathrm{~d}$ (total of $200 \mathrm{mg}$ ). On the third day of prednisone treatment, the glucagon (low dose) experiment was repeated, and on the fourth day of prednisone treatment the epinephrine experiment was repeated. To assess the effect of prednisone alone, the values obtained in the two basal periods after prednisone was averaged and compared with the average basal value for that individual before prednisone treatment. Similarly, the interactive effects of prednisone and epinephrine, and prednisone and glucagon, were assessed by comparing the responses with hormone infusion after prednisone treatment to the responses observed before prednisone was given.

Hyperglycemia experiments. In each of the above protocols, the plasma glucose concentration increased as a result of the treatment. Therefore, we performed another protocol in four subjects in which the response to hyperglycemia, independent of changes in insulin or glucagon, was assessed. Somatostatin, basal insulin, basal glucagon, and all isotopes were infused as described above. After basal values were obtained, unlabeled glucose was infused at the rate of $2 \mathrm{mg} / \mathrm{kg} \cdot \min$ for the next $90 \mathrm{~min}$. The 90 -min infusion of glucose was used to ensure that a new physiological steady state would be achieved.

Glucagon and insulin were obtained from Eli Lilly \& Co. (Indianapolis, IN) and E. R. Squibb \& Sons, Inc. (Princeton, NJ), respectively. Epinephrine was supplied by Upjohn Co. (Kalamazoo, MI). Each hormone-infusion mixture was mixed freshly each day. The epinephrine was diluted in saline containing ascorbic acid to prevent oxidation. Prednisone (Elkins Sinn, Cherry Hill, NJ) was given orally in 25-mg tablets.

In each experiment a blood sample was drawn before the start of the isotope infusion. After an initial $60 \mathrm{~min}$ for isotope equilibrium to be established, samples were drawn at 10-min intervals until the end of the experiment. In all cases period I ended after 90 min, meaning samples drawn at $60,70,80$, and 90 min were used to obtain basal values. The samples were then drawn at 10 -min intervals throughout the experimental perturbation in period II. Samples were analyzed for isotopic enrichment and concentration of glucose, FFA, and glycerol, as well as plasma concentrations of insulin, glucagon, and epinephrine.

\section{Analysis of samples}

The samples for glucagon and insulin analysis were collected in iced tubes containing $0.05 \mathrm{ml}$ of $15 \%$ EDTA and $0.2 \mathrm{mg}$ of aprotinin and centrifuged immediately. Plasma concentration of glucagon and insulin were determined by radioimmunoassay using 6-15 antibody obtained from Dr. Jonathan Jaspan of the University of Chicago (Chicago, IL) and a kit from Micromedic Systems Inc. (Horsham, PA), respectively. Plasma epinephrine concentration was measured by radioenzymatic assay (22). Plasma glucose concentration was measured on a Beckman glucose autoanalyzer.

Blood for analysis of glucose enrichment was collected in heparinized prechilled tubes. The blood was centrifuged immediately and the plasma was frozen until the time of analysis. The plasma proteins were precipitated and the supernatant passed sequentially through Dowex AG-1-X8 and AG-50W-X8 anion and cation exchange columns. For the determination of the enrichment of 6,6- $d_{2}$-glucose, the pentaacetate derivative was formed; for the determination of $2-d_{1}$-glucose enrichment, the trimethylsilyl derivative was formed. Measurement of 
isotopic enrichment of the two derivatives was performed using a Hewlett-Packard 5985 gas chromatograph mass spectrometer (GCMS). The ions at mass/charge ratio (m/e) 171:169 were selectively monitored using the chemical ionization mode to determine $6,6-d_{2}-$ glucose enrichment, and ions at m/e 205:204 were selectively monitored using electron impact ionization to determine $2-d_{1}$-glucose enrichment. By using these ions, the molecular fragments included the carbon position of interest (e.g., the 6 position), while excluding the other labeled position in the molecule (e.g., the 2 position). We have previously described the details of the mass spectrometry procedures (8).

Samples to be analyzed for palmitate enrichment were first processed for quantitative gas chromatography, with heptadecanoic acid $(0.05 \mathrm{mg} / \mathrm{ml}$ plasma) being added as an internal standard for subsequent measurement of FFA concentration by gas chromatography using a Hewlett-Packard gas chromatograph (22). After conversion to the methyl ester, $\left[1-{ }^{13} \mathrm{C}\right]$ palmitic acid enrichment was determined by GCMS as described previously (20).

The processing of samples for glycerol involved the addition of $\left[2-{ }^{13} \mathrm{C}\right]$ glycerol as an internal standard for concentration measurement, precipitation of proteins with $\mathrm{Ba}(\mathrm{OH})_{2}$ and $\mathrm{ZnSO}_{4}$, and passing the resultant supernatant sequentially through anion and cation exchange columns. The trimethylsilyl derivative was formed and isotopic enrichment determined by GCMS using electron-impact ionization (23). Ions were selectively monitored at $\mathrm{m} / \mathrm{e} 205,206$, and 208 in order to quantify the isotopic enrichment in the plasma resulting from the $d 5$-glycerol infusion ( $\mathrm{m} / \mathrm{e} \mathrm{208)}$ and the enrichment resulting from the in vitro addition of $\left[2-{ }^{13} \mathrm{C}\right]$ glycerol $(\mathrm{m} / \mathrm{e} 206)$ for the purpose of determining concentration.

\section{Calculations}

The rate of appearance of palmitate ( $R_{\mathrm{a}}$ palmitate), glycerol $\left(R_{\mathrm{a}}\right.$ glycerol), and glucose ( $R_{\mathrm{a}}$ glucose) were calculated using the same general approach.

In the basal period (samples 60-90 min), a physiological and isotopic steady state existed, meaning that neither concentration of substrate nor isotopic enrichment was changing over time. Under these conditions, $\boldsymbol{R}_{\mathrm{a}}$ was calculated as: $\boldsymbol{R}_{\mathrm{a}}$ (micromoles per kilogram times minutes $)=\left(\left[\mathrm{IE}_{\mathrm{f}}\right] /\left[\mathrm{IE}_{\mathrm{p}}\right]-1\right) F$, where $\mathrm{F}$ is the isotope infusion rate (micromoles per kilogram times minutes), $\mathrm{IE}_{\mathrm{f}}$ is the isotopic enrichment of the infusate, and $\mathrm{IE}_{\mathrm{p}}$ is the isotopic enrichment of plasma (mole percent excess) at isotopic equilibrium. We have discussed in detail elsewhere the use of this equation with stable isotope tracers (24).

Since palmitate is thought to be typical of other long-chain fatty acids, the relationship between flux and concentration of the other fatty acids in plasma was assumed to be the same as for palmitate. Therefore, $R_{\mathrm{a}}$ of total FFA $=R_{\mathrm{a}}$ of palmitate/[palmitate]/[total FFA], where [palmitate] and [total FFA] are the concentrations of palmitate and FFA, respectively.

The concentration of plasma glycerol was determined as follows: unlabeled glycerol (micromoles per milliliter) $=0.004 \mu \mathrm{mol} / \mathrm{ml} / \mathrm{MPE}$ -0.004 , when $0.004 \mu \mathrm{mol}$ of $\left[2-{ }^{13} \mathrm{C}\right] \mathrm{glycerol}$ was added to $1 \mathrm{ml}$ of each sample, and MPE is the mole percent excess of each sample as compared with a sample from the same subject without $\left[2-{ }^{13} \mathrm{C}\right]$ glycerol added.

After the administration of glucagon or epinephrine or unlabeled glucose, the steady state was disturbed. In this case, the nonsteady state form of the Steele equation was used (after curve fitting of raw data) (25). $\left.R_{\mathrm{a}}=F-V\left(C_{2}+C_{1}\right) / 2\right]\left[\left(\mathrm{IE}_{2}-\mathrm{IE}_{1}\right) /\left(t_{2}-t_{1}\right)\right] /\left(\mathrm{IE}_{2}+\mathrm{IE}_{1} / 2\right)$, where $C_{2}$ and $C_{1}$ are the concentrations at times $t_{2}$ and $t_{1}$, respectively; $\mathrm{IE}_{2}$ and $\mathrm{IE}_{1}$ are the enrichments at times $t_{2}$ and $t_{1}$, respectively; and $V$ is the effective volume of distribution of the substrate. $V$ was assumed to be $40 \mathrm{ml} / \mathrm{kg}$ for palmitate, $210 \mathrm{ml} / \mathrm{kg}$ for glycerol, and $150 \mathrm{ml} / \mathrm{kg}$ for glucose. During the hyperglycemia experiments, the rate of endogenous glucose production was calculated by subtraction of the glucose infusion rate from the calculated $R_{\mathrm{a}}$.

Rate of substrate cycling was calculated as follows: rate of glucose substrate cycling (micromoles per kilogram times minute) $=R_{\mathrm{a}}\left(2-d_{1}\right)$
- $R_{\mathrm{a}}\left(6,6-d_{2}\right)$, where $R_{\mathrm{a}}\left(2-d_{1}\right)$ is the $R_{\mathrm{a}}$ of glucose as calculated by the 2- $d_{1}-$ glucose, and $R_{\mathrm{a}}\left(6,6-d_{2}\right)$ is the $R_{\mathrm{a}}$ of glucose as calculated by the 6,6- $d_{2}$-glucose: rate of TG/FA substrate cycling (micromoles per kilogram times minutes) $=3 \times R_{\mathrm{a}}$ glycerol $-R_{\mathrm{a}}$ FFA. The rationale for this calculation is that for every glycerol released from triglyceride, three fatty acids must also be released from triglyceride. Thus, if fatty acids appear in the plasma at a rate less than three times $R_{\mathrm{a}}$ glycerol, some reesterification of fatty acid must have occurred.

\section{Statistical analysis}

The value after treatment was compared statistically with the basal value for the same group using the paired $t$ test. Comparison between groups were made using the nonpaired $t$ test.

\section{Results}

In all cases, an isotopic and physiologic steady state existed in period I. A representative example of isotope enrichment is shown in Fig. 1. Average values for isotopic enrichment do not reflect the steady state situation as clearly, since the standard error of each point does not distinguish between intrasubject variability (sample to sample) at equilibrium and intersubject variability resulting from different isotopic infusion rates and different turnover rates. Because a steady state was judged to have been achieved in each case, the basal values were consequently calculated by averaging the four basal enrichment values, and dividing into the isotopic infusion rate.

Glucagon experiments. The high dose infusion increased the glucagon concentration to $>5,000 \mathrm{pg} / \mathrm{ml}$, whereas the low dose infusion increased the glucagon concentration to form a basal value of $153 \pm 35$ to $453 \pm 56 \mathrm{pg} / \mathrm{ml}$ (mean \pm SEM). The plasma glucose concentration significantly increased after both glucagon infusions (Fig. 2). The infusion of somatostatin and insulin did not affect the extent to which low dose glucagon caused the glucose concentration to increase. The hyperglycemia during the high dose glucagon was more exaggerated than during the low dose protocols.

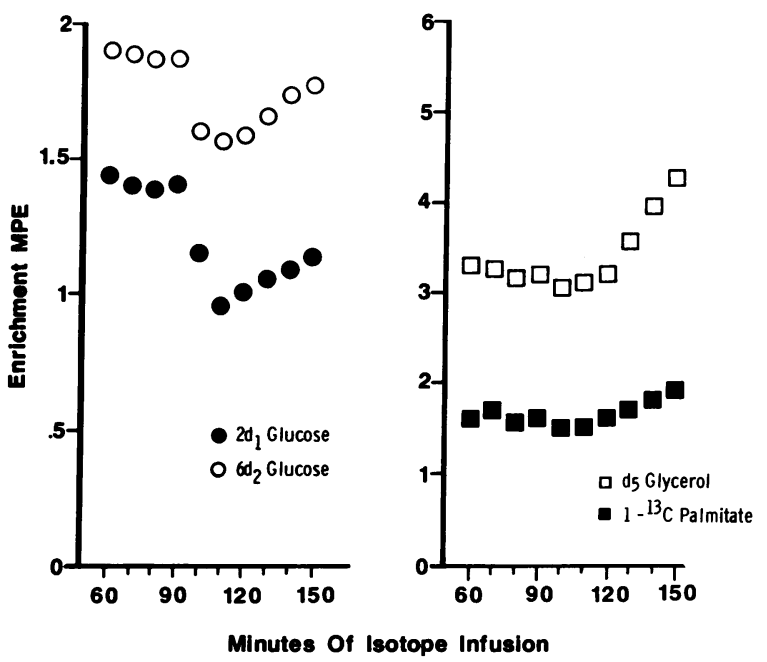

Figure 1. Representative example of glucose, palmitate, and glycerol enrichment from experiment in which the first 90 min involved only the tracer infusion, and from 90 to 150 min glucagon was infused at the rate of $6 \mathrm{ng} / \mathrm{kg} \cdot \mathrm{min}$. Isotope infusion rates for this experiment were as follows: $2-d_{1}$-glucose, $0.183 \mu \mathrm{mol} / \mathrm{kg} \cdot \mathrm{min} ; 6,6-d_{2}$-glucose, $0.178 \mu \mathrm{mol} / \mathrm{kg} \cdot \mathrm{min} ;\left[1-{ }^{13} \mathrm{C}\right] \mathrm{palmitate}, 0.036 \mu \mathrm{mol} / \mathrm{kg} \cdot \mathrm{min}$; and $d 5-$ glycerol, $0.097 \mu \mathrm{mol} / \mathrm{kg} \cdot \mathrm{min}$. Units for enrichment are mole percent excess (MPE). 


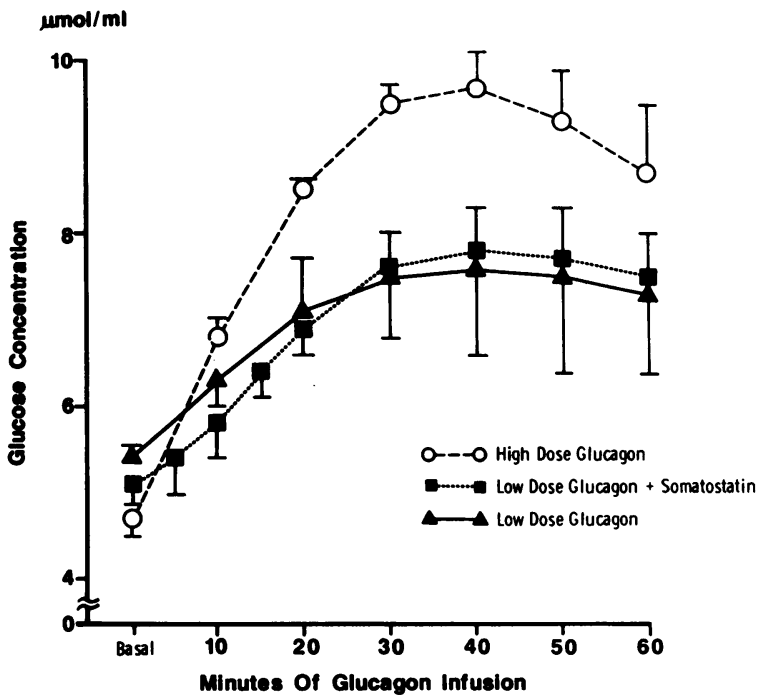

Figure 2. Glucose concentration before (basal) and during infusion of glucagon at $5 \mathrm{ng} / \mathrm{kg} \cdot \min$ (low dose glucagon), or $2 \mu \mathrm{g} / \mathrm{kg} \cdot \min$ (high dose glucagon). In the group given somatostatin (0.1 $\mu \mathrm{g} / \mathrm{kg} \cdot \mathrm{min}$ ), insulin was replaced at the rate of $0.1 \mathrm{mU} / \mathrm{kg} \cdot \mathrm{min}$ throughout the entire experiment. Glucagon was infused at 1 $\mathrm{ng} / \mathrm{kg} \cdot \min$ in the basal period, and then the infusion was increased to $6 \mathrm{ng} / \mathrm{kg} \cdot \mathrm{min}$ from 0 to $60 \mathrm{~min}$ of "glucagon infusion" period.

In the basal period, the insulin concentrations were comparable in all three groups (high dose glucagon, $10 \pm 1 \mu \mathrm{U} / \mathrm{ml}$; low dose glucagon, $8 \pm 1 \mu \mathrm{U} / \mathrm{ml}$; low dose glucagon plus somatostatin and insulin replacement, $8 \pm 1 \mu \mathrm{U} / \mathrm{ml}$; mean $\pm \mathrm{SE}$ ). After the high dose glucagon, insulin rose to an average value of $167 \pm 9 \mu \mathrm{U} / \mathrm{ml}$. The insulin concentration rose to $20 \pm 2 \mu \mathrm{U} / \mathrm{ml}$ after the low dose glucagon infusion. Insulin remained constant throughout the somatostatin protocol $(9 \pm 1 \mu \mathrm{U} / \mathrm{ml}$ after glucagon infusion). These data are presented in Fig. 3.

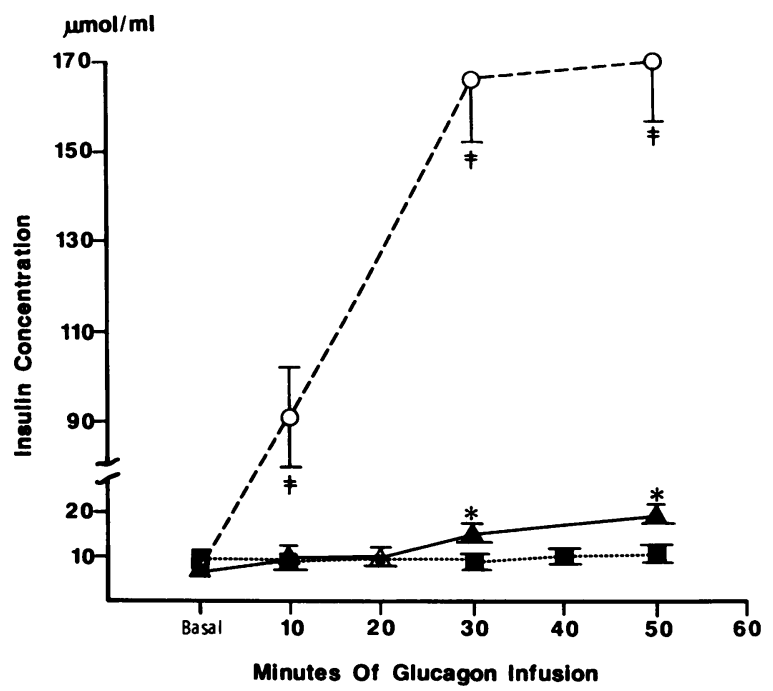

Figure 3. Insulin concentration during the infusion of high dose glucagon (0), low dose glucagon ( $\mathbf{\Delta})$, or low dose glucagon plus somatostatin and replacement insulin ( $(\mathbf{)}$. ‡Significantly different from low glucagon groups, $P<0.01$. Significantly different from low glucagon and somatostatin group.
The basal values for $R_{\mathrm{a}}\left(2-d_{1}\right)$ - and $R_{\mathrm{a}}\left(6,6-d_{2}\right)$-glucose, and glucose cycling, were similar in all groups (Figs. 4-7) (Table I). Both $R_{\mathrm{a}}\left(2-d_{1}\right)$ - and $R_{\mathrm{a}}\left(6,6-d_{2}\right)$-glucose were initially stimulated by glucagon infusion in all groups (Figs. 4-6). Without somatostatin infusion, these values peaked at $20 \mathrm{~min}$ and declined thereafter in both low and high dose glucagon groups. When somatostatin plus constant basal insulin was infused, the $R_{\mathrm{a}}\left(6,6-d_{2}\right)$-glucose response was similar to the response during the low dose infusion without somatostatin, but the increase in $R_{\mathrm{a}}\left(2-d_{1}\right)$-glucose was sustained throughout the entire infusion of glucagon (Fig. 6).

The responses of glucose cycling to glucagon are shown in Fig. 7. All three groups had significant increases in cycling after glucagon infusion. The peak value for glucose cycling was significantly higher $(P<0.05)$ in all cases than the corresponding basal value, as was the average value throughout the $60 \mathrm{~min}$ of glucagon infusion (Table I). Comparison of the low glucagon group versus the low glucagon plus somatostatin and basal insulin replacement group indicated a prolonged stimulation of cycling with somatostatin, since the values in the somatostatin group at 50 and $60 \mathrm{~min}$ were significantly greater than the corresponding values in the low dose glucagon group ( $P$ $<0.05$ ). No significant differences between the high and low dose glucagon groups could be determined.

Low dose glucagon did not significantly affect $R_{\mathrm{a}}$ glycerol or $R_{\mathrm{a}}$ FFA (Fig. 8). Similarly, $R_{\mathrm{a}}$ glycerol was constant during high dose glucagon but $R_{\mathrm{a}}$ FFA decreased from a basal value of $7.4 \pm 0.8 \mu \mathrm{mol} / \mathrm{kg} \cdot \min$ to a low value of $3.0 \pm 0.5 \mu \mathrm{mol} /$ $\mathrm{kg} \cdot \mathrm{min}$. The fall in $R_{\mathrm{a}}$ FFA was not immediate but corresponded to the inverse of the pattern of the change in glucose concentration.

Similarly, low dose glucagon had no effect on TG/FA cycling (Table II). The high dose glucagon group had an increase in TG/FA cycling, due to an increased rate of reesterification of fatty acids, while lipolysis $\left(R_{\mathrm{a}}\right.$ glycerol) remained constant.

Low dose glucagon with somatostatin had no significant effect on $R_{\mathrm{a}}$ glycerol, $\boldsymbol{R}_{\mathrm{a}}$ FFA, and TG/FA cycling (Table II).

Epinephrine experiments. The epinephrine concentration increased from a basal value of $106 \pm 19$ to $453 \pm 56 \mathrm{pg} / \mathrm{ml}$ (mean $\pm \mathrm{SE}$ ) during the epinephrine infusion.

Epinephrine infusion caused a modest increase in both $R_{\mathrm{a}}\left(2-d_{1}\right)$ - and $R_{\mathrm{a}}\left(6,6-d_{2}\right)$-glucose (Fig. 9), but did not cause a significant effect on glucose cycling (Table I). Plasma glucose concentration nonetheless increased significantly, from a basal value of $4.8 \pm 0.2 \mu \mathrm{mol} / \mathrm{ml}$ to a peak value of $5.9 \pm 0.3 \mu \mathrm{mol} / \mathrm{ml}$ (mean $\pm \mathrm{SE}, P<0.05$ ). Insulin concentration did not increase significantly.

On the other hand, the stimulatory effect of epinephrine on TG/FA cycling was significant (Table II), owing to the fact that three times $R_{\mathrm{a}}$ glycerol increased more than did $\boldsymbol{R}_{\mathrm{a}}$ FFA (Fig. 10). However, the effect of epinephrine on lipolysis was transient, and therefore the overall average rate of cycling during epinephrine infusion was not significantly elevated (Table II).

Prednisone experiments. Prednisone treatment caused a significant increase in the plasma glucose concentration, from $4.8 \pm 0.2 \mu \mathrm{mol} / \mathrm{ml}$ before prednisone to $5.4 \pm 0.2 \mu \mathrm{mol} / \mathrm{ml}$ after prednisone $(P<0.05)$. Insulin concentration also significantly increased from $9 \pm 1 \mu \mathrm{U} / \mathrm{ml}$ before prednisone to $17 \pm 2 \mu \mathrm{U} / \mathrm{ml}$ after prednisone $(P<0.05)$. There were no significant effects of prednisone alone on basal glucose or TG/FA cycling (Tables I and II). The response to glucagon infusion of $R_{\mathrm{a}}\left(2-d_{1}\right)$ - and 
Table I. Glucose Substrate Cycling

\begin{tabular}{|c|c|c|c|c|c|c|c|}
\hline & $\begin{array}{l}\text { Low dose glucagon } \\
\qquad(n=4)\end{array}$ & $\begin{array}{l}\text { High dose glucagon } \\
\qquad(n=4)\end{array}$ & $\begin{array}{l}\text { Low dose glucagon } \\
\text { plus somatostatin } \\
\qquad(n=4)\end{array}$ & $\begin{array}{l}\text { Epinephrine } \\
\qquad(n=6)\end{array}$ & $\begin{array}{l}\text { Prednisone plus low } \\
\text { dose glucagon } \\
(n=4)\end{array}$ & $\begin{array}{l}\text { Prednisone plus } \\
\text { epinephrine } \\
\quad(n=6)\end{array}$ & $\begin{array}{c}\text { Glucose plus } \\
\text { somatostatin } \\
\quad(n=4)\end{array}$ \\
\hline Basal & $5.3 \pm 0.9$ & $4.4 \pm 0.8$ & $6.8 \pm 1.6$ & $3.4 \pm 0.8$ & $4.9 \pm 0.7$ & $2.9 \pm 0.8$ & $6.4 \pm 1.3$ \\
\hline Peak value & $18.0 \pm 1.9^{*}$ & $25.8 \pm 6.0^{*}$ & $23.5 \pm 2.4^{*}$ & $6.9 \pm 2.3$ & $7.7 \pm 1.7$ & $9.8 \pm 3.2$ & $10.5 \pm 3.8$ \\
\hline Average value & $12.4 \pm 1.9^{*}$ & $19.2 \pm 4.8^{*}$ & $15.8 \pm 2.7^{*}$ & $5.7 \pm 1.2$ & $6.7 \pm 1.2$ & $7.4 \pm 2.3$ & $7.0 \pm 3.0$ \\
\hline
\end{tabular}

Units are micromoles per kilogram times minutes. Values are mean \pm SE. ${ }^{*}$ Significantly different from basal value $(P<0.05)$.

$R_{\mathrm{a}}\left(6,6-d_{2}\right)$-glucose, as well as the rate of glucose cycling, was markedly blunted by prednisone (Fig. 4) (Table I). $R_{\mathrm{a}}$ FFA and $R_{\mathrm{a}}$ glycerol were not affected by glucagon infusion after prednisone treatment (Fig. 8). Prednisone treatment did not modify the response of either glucose cycling or TG/FA cycling to epinephrine infusion (Tables I and II) (Figs. 9 and 10).

Hyperglycemia experiment. The role of hyperglycemia in regulating glucose and TG/FA cycling was assessed, since all hormone infusions caused increases in glucose concentration. Plasma glucose concentration increased from a basal value of $5.3 \pm 0.4 \mu \mathrm{mol} / \mathrm{ml}$ to a value of $9.3 \pm 0.6 \mu \mathrm{mol} / \mathrm{ml}$ (mean $\pm \mathrm{SE}, P$ $<0.05$ ) in this group. Basal values for $R_{\mathrm{a}}$ in this group were comparable with corresponding values in other groups (Figs. 11 and 12). Hyperglycemia caused a significant suppression of endogenous glucose production when assessed with 6,6- $d_{2-}$ glucose $(P<0.05)$, but the average reduction in $R_{\mathrm{a}}\left(2-d_{1}\right)$-glucose was not statistically significant (Fig. 11). Consequently, the calculated value for glucose cycling increased slightly, but not significantly (Table I). Hyperglycemia, in the absence of changes in glucagon and insulin, caused slight but significant reductions in both $R_{\mathrm{a}}$ glycerol and $R_{\mathrm{a}}$ FFA $(P<0.05)$ (Fig. 12), but the calculated increase in TG/FA cycling was not signifcant (Table II).

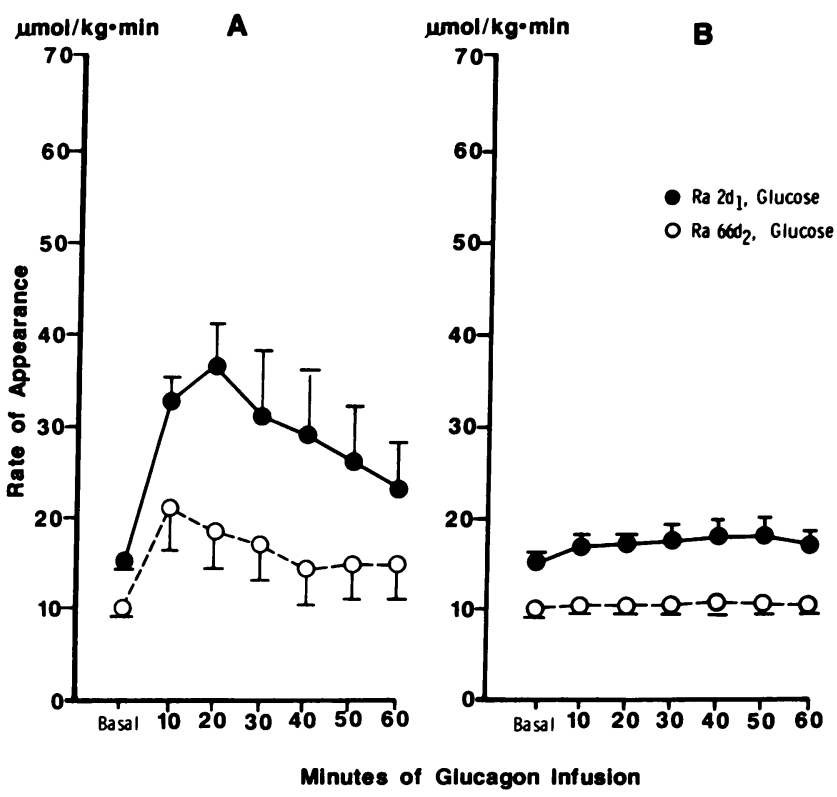

Figure 4. $R_{\mathrm{a}}$ of glucose calculated with different tracers to low dose glucagon infusion before $(A)$ and after $(B) 3 \mathrm{~d}$ of treatment with prednisone.

\section{Discussion}

Although substrate cycles were proposed over twenty years ago to be important in the regulation of energy metabolism (1), the assessment of substrate cycling in human subjects has only recently been undertaken (8-14). Whereas these recent studies have established the existence of substrate cycling in humans, there is little evidence regarding the factors regulating the rate of cycling. In this study we have assessed the acute response to elevations in glucagon and epinephrine, as well as the response to a chronic elevation in glucocorticoid activity. Our results indicate that glucagon markedly stimulates glucose cycling, but has little direct effect on TG/FA cycling. In contrast, epinephrine stimulates TG/FA cycling, but has minimal effect on glucose cycling. The glucagon effect on glucose cycling is counteracted by an inhibitory action of insulin, but hyperglycemia does not affect either glucose or TG/FA cycling. We did not observe a direct effect of glucocorticoid treatment on either glucose or TG/FA cycling, but the response of glucose cycling to glucagon was blunted after glucocorticoid treatment.

The rationale for the use of glucose labeled in different positions to quantify glucose cycling derives from the different

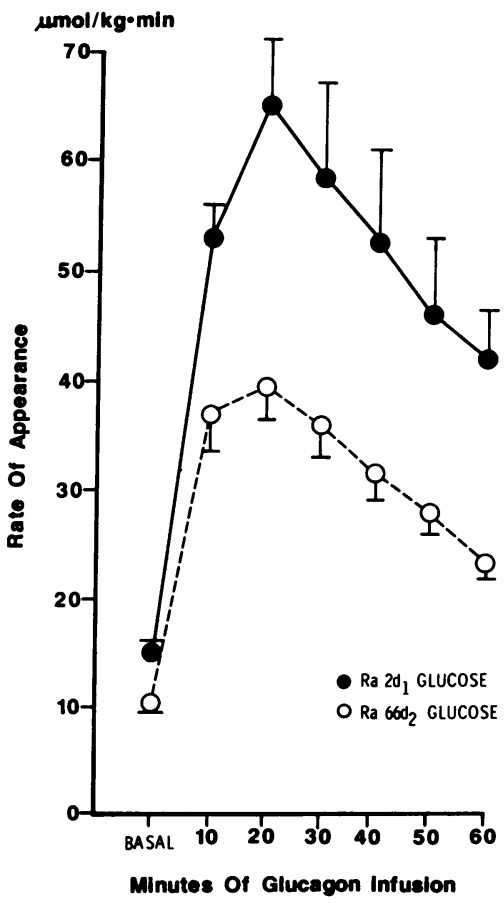

Figure 5. Effect of high dose glucagon infusion on glucose $R_{\mathrm{a}}$ calculated with different tracers. 


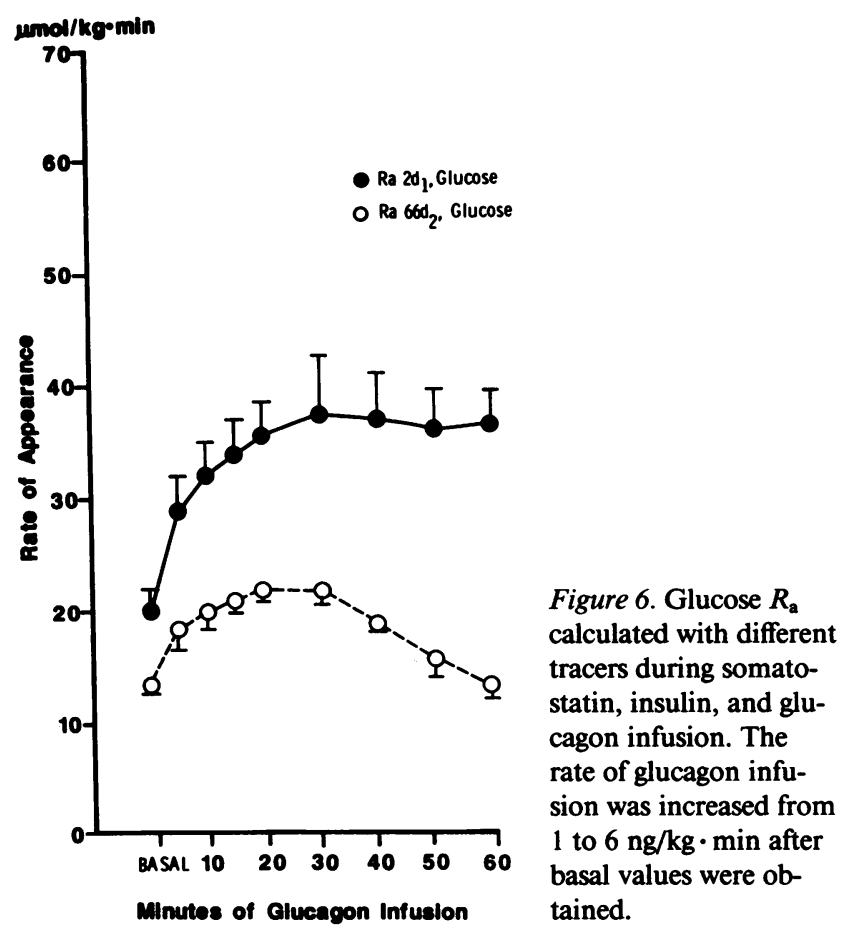

steps in the metabolism of glucose at which the hydrogen (or deuterium) is lost. The deuterium at position 2 is lost in the phosphoglucose isomerase step, so most label will be removed before glucose-6-phosphate leaves to become either glycogen or advances through glycolysis, or recycles back to glucose. Therefore, a molecule that cycles through the glucose/glucose6-phosphate cycle will lose the deuterium at position 2 , but not

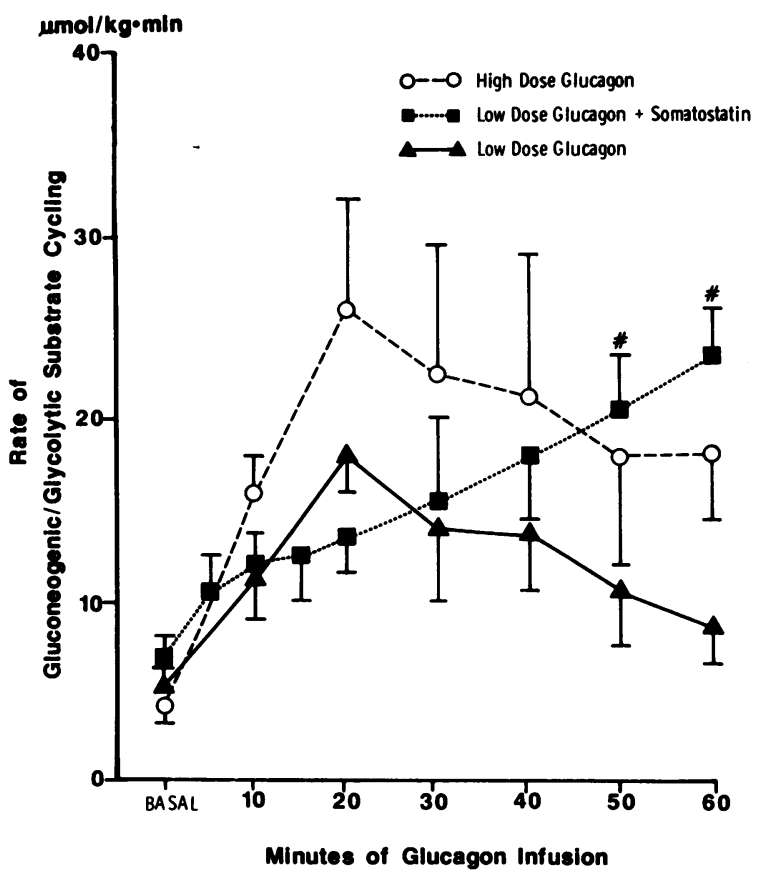

Figure 7. Rate of gluconeogenic/glycolytic substrate cycling after glucagon infusion. \#Significant difference $(P<0.05)$ from low dose glucagon infusion (without somatostatin).

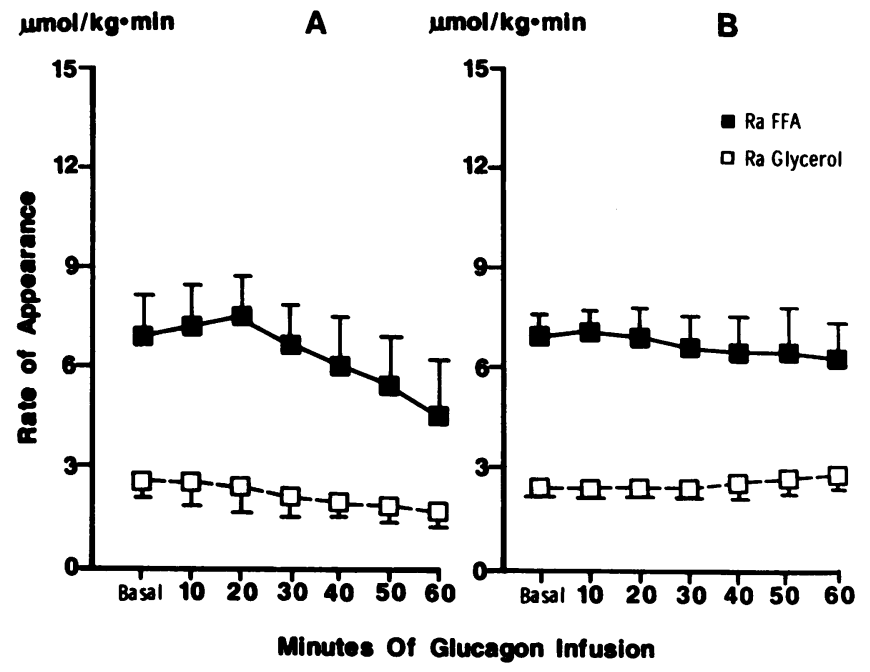

Figure 8. Effect of low dose glucagon infusion before $(A)$ and after $(B)$ prednisone treatment on the $R_{\mathrm{a}}$ of glycerol and FFA.

the deuterium from position 6 . The deuterium from position 6 of glucose is lost during carboxylation of pyruvate into oxaloacetate, and equilibrium with dicarboxylic acids. Thus, if a molecule cycles through the glucose cycle (glucose/glucose6P-glucose) it will lose the label in the 2 position, but not in the 6 position. Consequently, the difference between the $R_{\mathrm{a}}$ of glucose as calculated using the different tracers will reflect the rate of glucose cycling.

There is little possibility that this method of estimating the rate of glucose cycling will overestimate the true values by virtue of glucose going to glycerol-6P, being incorporated into triglyceride, then released as glycerol and reincorporated into glucose. Although this pathway would theoretically add to the calculation of $R_{\mathrm{a}} 2-R_{\mathrm{a}} 6$ (since the $2 \mathrm{D}$ would be lost but the $6 \mathrm{D}$ would be retained), the quantitative aspect of this cycle is virtually nil. Using a high rate of infusion of $\left[1{ }^{13} \mathrm{C}\right] g l u c o s e$, we found that $<1 \%$ of the glycerol flux is derived from plasma glucose labeled (15). Since the percentage contribution of glycerol to glucose output in postabsorptive man is $<5 \%$ (26), the amount of apparent glucose substrate cycling that might actually be occurring by this alternative route is insignificant.

The interpretation that the difference between $R_{\mathrm{a}} 2$ and $R_{\mathrm{a}} 6$ equals the rate of glucose cycle activity varies from our previous claim that $R_{\mathrm{a}} 2-R_{\mathrm{a}} 6$ equaled the sum of the glucose and the fructose cycles (8). The rationale for our previous interpretation was that a substrate cycle in the metabolism of glucose could be quantified if a label in one position of glucose is lost in that cycle, while a label from another position is not lost. In that case, the rate of the glucose cycle would equal $R_{\mathrm{a}} 2-R_{\mathrm{a}} 3$ (since the 3 deuterium is not lost in the glucose cycle), and the rate of the fructose cycle would equal $R_{\mathrm{a}} 3-R_{\mathrm{a}} 6$ (since the 6 deuterium is lost in the fructose cycle, and the 6 deuterium are not lost). This general approach has been used by others for calculation of both the rate of the glucose cycle $(14,27,28)$ and the fructose cycle (29). If each substrate cycle is calculated as described above, then, the sum of the two cycles would be equal $\left(R_{\mathrm{a}} 2-R_{\mathrm{a}} 3\right)+\left(R_{\mathrm{a}} 3-R_{\mathrm{a}} 6\right)=R_{\mathrm{a}} 2-R_{\mathrm{a}} 6$. However, whereas there is general agreement that $R_{\mathrm{a}} 3-R_{\mathrm{a}} 6$ provides a reflection of fructose cycle activity, it is now evident to us that 
Table II. TG/FA Substrate Cycling

\begin{tabular}{|c|c|c|c|c|c|c|c|}
\hline & $\begin{array}{l}\text { Low dose glucagon } \\
\qquad(n=4)\end{array}$ & $\begin{array}{l}\text { High dose glucagon } \\
\qquad(n=4)\end{array}$ & $\begin{array}{l}\text { Low dose glucagon } \\
\text { plus somatostatin } \\
\qquad(n=4)\end{array}$ & $\begin{array}{l}\text { Epinephrine } \\
\qquad(n=6)\end{array}$ & $\begin{array}{l}\text { Prednisone plus low } \\
\text { dose glucagon } \\
\quad(n=4)\end{array}$ & $\begin{array}{l}\text { Prednisone plus } \\
\text { epinephrine } \\
(n=6)\end{array}$ & $\begin{array}{l}\text { Glucose plus } \\
\text { somatostatin } \\
\quad(n=4)\end{array}$ \\
\hline Basal & $0.7 \pm 1.0$ & $0.9 \pm 0.9$ & $1.2 \pm 0.3$ & $0.4 \pm 0.4$ & $0.5 \pm 0.3$ & $0.4 \pm 0.5$ & $0.4 \pm 0.3$ \\
\hline Peak value & $0.6 \pm 0.8$ & $4.8 \pm 0.7^{*}$ & $1.4 \pm 0.1$ & $4.9 \pm 0.9^{*}$ & $2.1 \pm 0.9$ & $6.4 \pm 2.7^{*}$ & $1.0 \pm 0.6$ \\
\hline Average value & $0.1 \pm 0.2$ & $3.8 \pm 0.7^{*}$ & $1.1 \pm 0.2$ & $1.0 \pm 0.5$ & $0.7 \pm 0.4$ & $2.5 \pm 2.2$ & $0.7 \pm 0.3$ \\
\hline
\end{tabular}

Units are micromoles per kilogram times minutes. Values are mean \pm SE. * Significantly different from basal value $(P<0.05)$.

the use of $R_{\mathrm{a}} 2-R_{\mathrm{a}} 3$ as a reflection of glucose cycle activity is valid only when hepatic fructose cycling is zero. Although this appears to be the case in postabsorptive humans (11), the lack of universality of the definition of $R_{\mathrm{a}} 2-R_{\mathrm{a}} 3$ invalidates the extrapolation described above that led us to the conclusion that $R_{\mathrm{a}} 2-R_{\mathrm{a}} 6$ equals the sum of glucose plus fructose cycling.

A more appropriate manner in which to interpret the glucose data is that $R_{\mathrm{a}} 2$ measures all new glucose production, plus that which has cycled through the glucose cycle, while $R_{\mathrm{a}} 6$ measures only new glucose production. Therefore, $R_{\mathrm{a}} 2-R_{\mathrm{a}} 6$ equals the rate of glucose cycle activity.

There is general agreement that glucose cycling occurs in normal human subjects in the postabsorptive state, but there is some discrepancy in the precise quantitation of that rate. Two other studies in which glucose cycling was determined with radioisotopes in normal volunteers have recently been reported $(10,11)$, and both papers reported rates of cycling that were lower than the value we have reported using stable isotopes. We have recently found that a systematic difference between radioisotopes and stable isotopes cannot explain this discrepancy. In a separate study we have compared the $\boldsymbol{R}_{\mathrm{a}}$ of glucose as determined simultaneously with 2-D-glucose $\left(R_{\mathrm{a}} 2 \mathrm{D}\right)$ and $\left[2-{ }^{3} \mathrm{H}\right]$ glucose $\left(R_{\mathrm{a}} 2^{3} \mathrm{H}\right)$ in conscious rats. The average values for $R_{\mathrm{a}} 2 \mathrm{D}$ and $R_{\mathrm{a}} 2^{3} \mathrm{H}$ were $5.85 \pm 0.29$ and $5.98 \pm 0.34$

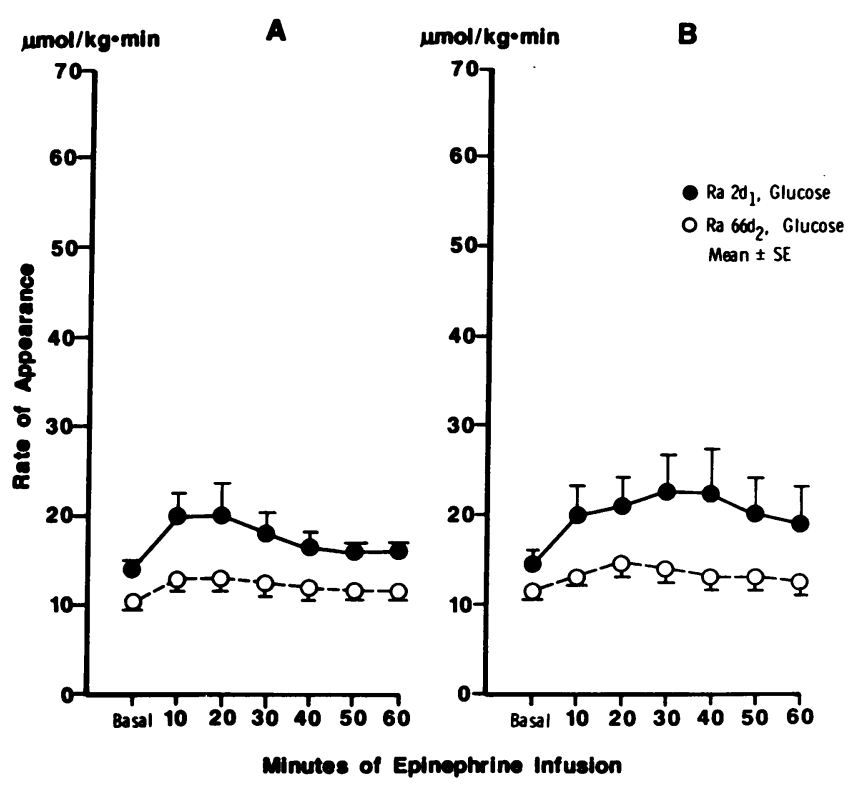

Figure 9. Effect of epinephrine infusion $(0.03 \mu \mathrm{g} / \mathrm{kg} \cdot \min )$ on $R_{\mathrm{a}}$ of glucose calculated with different tracers before $(A)$ and after $(B)$ prednisone treatment. $\mathrm{mg} / \mathrm{kg} \cdot \mathrm{min}$, respectively (unpublished observation). These values are obviously not different. It is possible that the differences in cycling rates between the various studies in humans simply reflects the difficulty of precise quantitation of all necessary factors, rather than any systemic differences. Thus, Bell et al. (10) reported a value for $R_{\mathrm{a}} 2^{3} \mathrm{H}$ of $15 \mu \mathrm{mol} / \mathrm{kg} \cdot \mathrm{min}$, almost precisely equal to our overall average value of 14.6 $\mu \mathrm{mol} / \mathrm{kg} \cdot \mathrm{min}$. Although Karlander et al. (11) reported a lower value for $R_{\mathrm{a}} 2^{3} \mathrm{H}(12.1 \mu \mathrm{mol} / \mathrm{kg} \cdot \mathrm{min})$, their value for $R_{\mathrm{a}} 6^{3} \mathrm{H}$ of $10.3 \mu \mathrm{mol} / \mathrm{kg} \cdot \min$ was similar to our value for $R_{\mathrm{a}} 6 \mathrm{D}$ of 9.8 $\mu \mathrm{mol} / \mathrm{kg} \cdot \mathrm{min}$. We are confident that our method of analysis induced no bias that would have resulted in an overestimation of $R_{\mathrm{a}} 2-R_{\mathrm{a}} 6$. First, there was no possibility of crosscontamination of isotopic enrichment at the two positions. The fragment used to analyze the enrichment of 2-D-glucose has a structure of $\left[\left(\mathrm{CH}_{3}\right)_{3} \mathrm{SiOC} \stackrel{2}{\mathrm{C}} \stackrel{3}{\mathrm{C}} \mathrm{HOSi}\left(\mathrm{CH}_{3}\right)_{3}\right]^{+}$, whereas the structure of the fragment used to analyze $6,6-d_{2}$-glucose enrichment is $\left(\mathrm{C}_{2} \mathrm{H}_{3} \mathrm{O}_{2} \stackrel{6}{\mathrm{C}} \mathrm{H}_{2} \stackrel{5}{\mathrm{C}} \stackrel{4}{\mathrm{C}} \mathrm{H} \mathrm{HC}_{2} \mathrm{O}_{2} \mathrm{H}_{3}\right)^{+}$. Thus, enrichment at the 2 position could not affect the apparent enrichment at the 6 position, or vice versa. Since both fragments exclude the 1 position, any deuterium that was not lost from the 6 position and was subsequently recycled into glucose would not be considered in the measurement of the enrichment of 2-D-glucose. Furthermore, the 6-D enrichment would not be significantly affected by such recycling either, since the mass increase due to recycling would be reflected by an increase in the ratio of $\mathrm{m} / \mathrm{e}$ 170:169, and would not have a noticeable effect on the ratio of

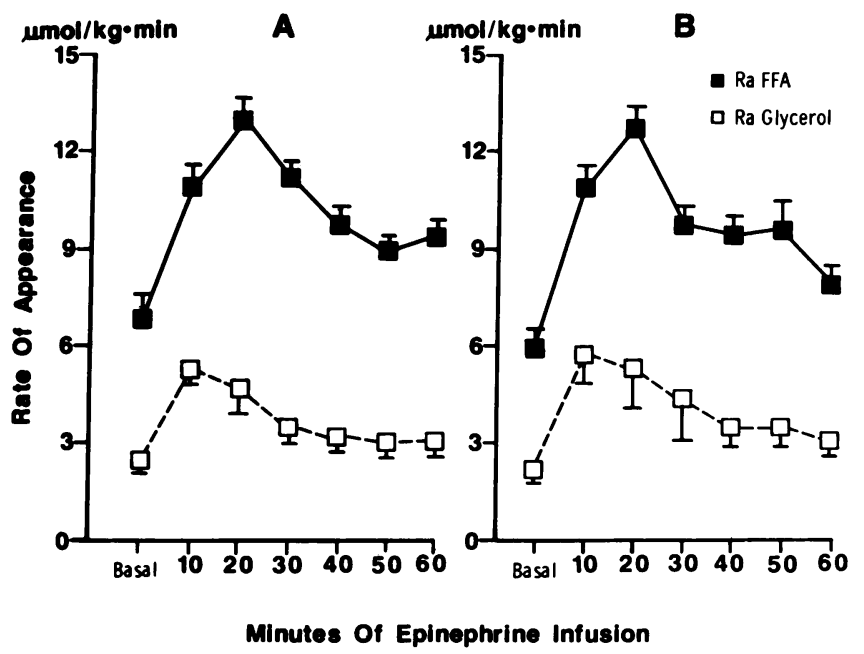

Figure 10. Effect of epinephrine infusion on the $R_{\mathrm{a}}$ of FFA and glycerol before $(A)$ and after $(B)$ prednisone treatment. 


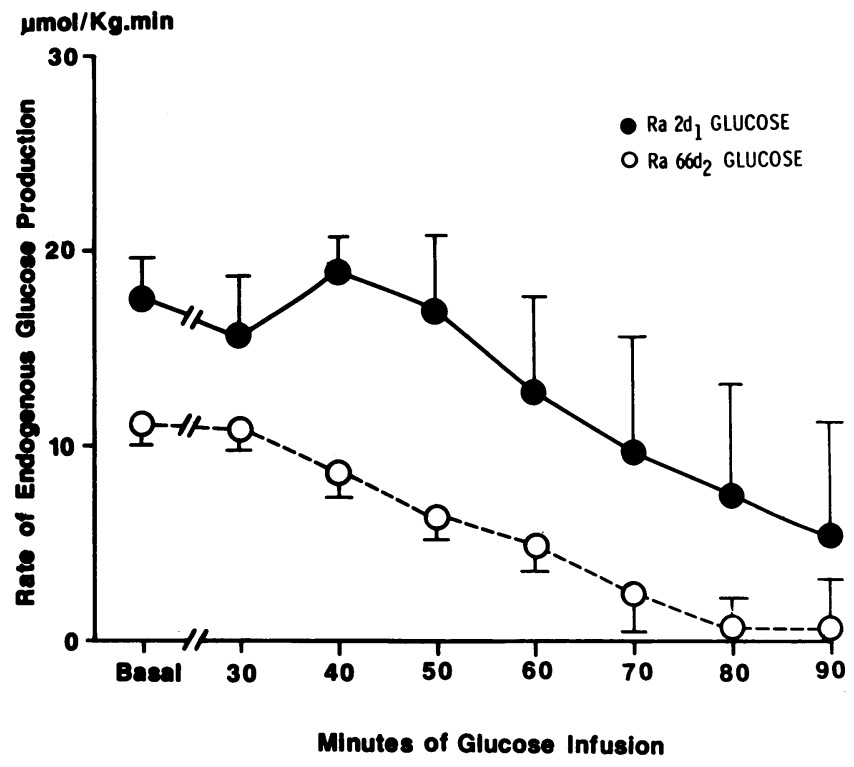

Figure 11. Effect of glucose infusion $(2 \mathrm{mg} / \mathrm{kg} \cdot \mathrm{min})$ on rate of endogenous glucose production calculated with different tracers.

m/e 171:169, which was used to monitor the enrichment of $6,6-d_{2}$-glucose. The technique we used to measure isotopic enrichment can reliably determine the known levels of natural abundance of stable isotopes of a glucose standard, and the coefficient of variation on five repeat analyses of the same sample (in the range of isotopic enrichment used in this study) is consistently below $2 \%$. Finally, because of mass spectrum identification, there is little possibility of contamination of the glucose peak with another compound that would cause spurious analysis of glucose enrichment.

There are several potential sources of errors in the analysis of specific activity of different positions of glucose. In the method used by Karlander et al. (11), the radioactivity in the 1 position is not distinguished from that in position 2 , thus the

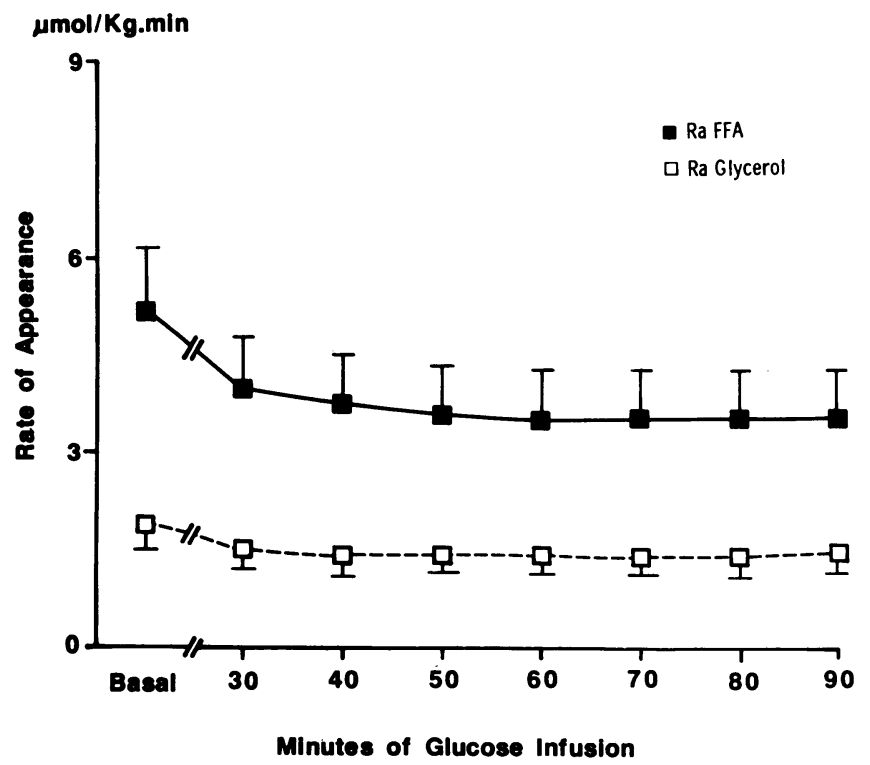

Figure 12. Effect of glucose infusion on the $R_{\mathrm{a}}$ of FFA and glycerol. possibility of recycled ${ }^{3} \mathrm{H}$ from the 6 position contributing to the apparent enrichment at the 2 position is not excluded. This would cause an underestimation of $R_{\mathrm{a}} 2^{3} \mathrm{H}$. In contrast, the detritiation procedure used by Bell et al. (10) to determine the specific activity in position 2 should exclude any enrichment in position 1. This could be the explanation of why Karlander et al. (11) obtained a slightly lower value for $R_{\mathrm{a}} 2$ than either Bell et al. (10) or ourselves. Another possible problem in the radioactive technique is that, regardless of the method of separation of the 2 and 6 positions, the untestable assumption must be made that with each sample the ion exchange chromatography successfully eliminates $100 \%$ of other labeled compounds, such as lactate and alanine. If this is not accomplished, the difference between $R_{\mathrm{a}} 2$ and $R_{\mathrm{a}} 6$ will be underestimated with either technique. Another potential problem in the radioactive techniques is the uncertain extent to which complete separation of the activity of the 2 and 6 positions is accomplished. This was reported to vary between 86 and $97 \%$ by Karlander et al. (11), but it is not clear how the recovery of each individual sample processed was determined. Also, due to limitations in the amount of radioactivity that can be administered to human subjects, low counts are obtained, leading to less precision in determining specific activity. Finally, it is erroneous to assume that the true value for glucose cycling in the volunteers studied by Karlander et al. (11) was the same as for our subjects, as our subjects were much younger (age range, 20 to 32 yr) than their subjects (age range, 33 to $60 \mathrm{yr}$ ). Given all the potential pitfalls of both the stable and radioisotope techniques, and the differences in the subjects studied, it is interesting that the calculated values from the different studies are as close as they are. In the context of the present study, we place more emphasis on the relative changes in cycling rates induced by specific treatments than with the exact rate of glucose cycling in absolute terms.

The interpretation of the 2- $d_{1^{-}}$and 6,6- $d_{2}$-glucose data would be complicated if some $6,6-d_{2}$-glucose was incorporated into hepatic glycogen during the basal period, then released as a consequence of hormone infusion. In that case, the apparent stimulation of glucose cycling during hormone infusion would not reflect the simultaneous activity of glucokinase and glucose-6-phosphatase, but rather only the activity of glucose-6phosphatase, since the labeled glucose coming from glycogen breakdown would have been incorporated into the glycogen in the preceding period. However, our results argue against this being an important problem. In the fasting (basal) state, little glycogen synthesis would be expected. Secondly, epinephrine is known to be a potent stimulator of glycogen breakdown, yet only a minor increase in glucose cycling was observed during epinephrine infusion. Thirdly, the magnitude of the increase in glucose cycling after glucagon was large compared with any artifact due to release of isotope from glycogen. In the basal period, glucose uptake averaged $11 \mu \mathrm{mol} / \mathrm{kg} \cdot \mathrm{min}$, or $\sim 1,000$ $\mu \mathrm{mol} / \mathrm{kg}$ over the $90-\mathrm{min}$ period. Since the volunteers were fasting, the assumption that $10 \%$ of this glucose uptake (100 $\mu \mathrm{mol} / \mathrm{kg}$ ) went directly to glycogen would almost certainly be an overestimate. Nonetheless, even if that large estimate of hepatic glycogen synthesis during fasting is assumed, and in the further unlikely event that glucagon infusion stimulated the complete release of all of that newly synthesized glycogen, this would still account for $<10 \%$ of the increase in glucose cycling over the 60 min during the high dose glucagon infusion 
$(1,140 \mu \mathrm{mol} / \mathrm{kg})$ (Table I). Consequently, there is little doubt that glucagon stimulates glucose cycling.

The stimulation of glucose cycling by glucagon might have been expected, on the one hand, since the stimulation of glucose-6-phosphatase by glucagon is well established (30). On the other hand, increased glucose cycling also requires a simultaneous increase in glucokinase activity. Although it has been shown that glucagon must be present for the maintenance of the regular activity of glucokinase (30), a direct stimulatory effect of glucagon on glucokinase has not been demonstrated. However, hyperglycemia does stimulate glucokinase (30). Consequently, the increased glucose cycling during glucagon infusion may have been the combined result of direct stimulation of glucose-6-phosphatase by glucagon, and the stimulation of glucokinase by the resulting hyperglycemia. If hyperglycemia was responsible for the stimulation of glucokinase, an insulin response to the hyperglucagonemia/hyperglycemia was not necessary for such an effect. In fact, comparison of the glucose cycling responses in the low dose glucagon groups with and without somatostatin plus insulin replacement leads to the conclusion that insulin inhibits glucose cycling. Glucose cycling decreased during the low dose glucagon infusion coincidental with the rise in insulin concentration, and when the insulin concentration was held constant throughout the glucagon infusion, glucose cycling continued to increase throughout the infusion period. The finding of an inhibitory effect of insulin on glucose cycling is consistent with the results reported by Efendic et al. (14), who found that elevated glucose cycling was a characteristic of early type two diabetes. These investigators concluded that normally functioning insulin is necessary for the suppression of glucose cycling (14). However, the results from our experiment in which high dose glucagon was infused might appear to be at odds with this conclusion, since the glucose cycling rate was elevated despite a large increase in insulin concentration. Alternatively, it is likely that this insulin response dampened what would have been an even larger, and more sustained, increase in cycling had the insulin response been blocked with somatostatin. The peak in glucose cycling during high dose glucagon was reached by 20 min of infusion, at a time when the insulin response had not yet reached maximum (Fig. 3). As the insulin reached the maximum levels later in the infusion, the glucose cycling decreased, despite a persistently high concentration of glucagon.

A potential complication of the use of somatostatin plus insulin replacement is that growth hormone secretion is also suppressed by somatostatin. It is possible that growth hormone might affect glucose cycling, as it has recently been reported that acromegalic patients with marked increases in growth hormone concentration had a significant increase in glucose cycling (12). However, the magnitude of the increase in these patients was small $(1.0 \mu \mathrm{mol} / \mathrm{kg} \cdot \mathrm{min})$, raising the possibility that less extreme variations in growth hormone would not affect glucose cycling at all. This possibility is supported by the fact that growth hormone infusion in normal volunteers had no effect on basal glucose production $(31,32)$. Furthermore, in our study when somatostatin was infused growth hormone was suppressed throughout both the basal and experimental periods, so any effect of increasing the glucagon infusion rate could not be ascribed to a change in growth hormone. Thus, it is extremely unlikely that failure to replace growth hormone when somatostatin was infused in any way influenced our conclusions regarding the effect of glucagon or glucose substrate cycling.

Two potential types of TG/FA cycle activity are possible in vivo: "intracellular," in which the FFA never leave the adipocyte before reesterification, and "extracellular," in which the FFA are released into the plasma, whereupon they are cleared from the plasma and reesterified. We have previously described how both of these pathways can be determined in humans (15). The calculation of the extracellular recycling requires knowledge of the total rate of fat oxidation, which can be determined by indirect calorimetry. In the present study, however, we were unable to quantify the rate of total fat oxidation during hormone infusion. The response to each hormone was transient, and our ability to measure oxygen consumption and $\mathrm{CO}_{2}$ production was not sufficiently accurate to quantify substrate oxidation in a rapidly changing nonsteady state. Consequently, we have calculated only intracellular TG/FA cycling. Since it is assumed that all fatty acids that do not enter the plasma are reesterified, the calculation of intracellular recycling overestimates the process by the amount of fatty acids that do not enter the sampled plasma pool before oxidation. Nonetheless, in our experience, changes in intracellular cycling correspond closely to changes in total cycling $(9,15)$.

The results from in vitro studies have suggested a stimulatory effect of glucagon on lipolysis $(17,18)$. Our results indicate that this effect may occur in vivo as well, since $R_{\mathrm{a}}$ glycerol was maintained despite the elevation in plasma glucose and insulin concentration. Increases in either insulin or glucose concentration would have been expected normally to reduce $R_{\mathrm{a}}$ glycerol by themselves (15), as seen in Fig. 12 . However, the physiological significance of the glucagon effect on lipolysis is minimal, since the amount of FFA mobilized during glucose infusion actually decreased modestly, presumably reflecting the direct inhibitory effect of glucose on lipolysis (Fig. 12), as well as the stimulatory effect of glucose and insulin on reesterification (15). The stimulatory effect of high dose glucagon on TG/FA cycling was almost certainly due to the resultant hyperglycemia and hyperinsulinemia stimulating reesterification, since $R_{\mathrm{a}}$ glycerol was no higher than during low dose glucagon infusion, when cycling was not significantly increased and the plasma glucose and insulin levels were much lower.

Whereas the predominant effect of glucagon is on glucose kinetics, epinephrine primarily exerts its effect on lipid kinetics. However, the direct effect of epinephrine on lipolysis (as reflected by $R_{\mathrm{a}}$ glycerol) can only be observed in the early phase of response (first $20 \mathrm{~min}$ ), because the resulting increase in plasma glucose concentration counteracts the lipolytic effect of epinephrine. It seems likely that epinephrine exerts an effect not only on lipolysis but also on reesterification. Although plasma glucose concentration rose during epinephrine infusion, the peak in TG/FA cycling occurred at $\sim 10-20$ min of epinephrine infusion. At this time the plasma glucose concentration had risen only modestly. Thus, it may be that stimulation of lipolysis is accompanied by a certain increase in direct reesterification due to an increase in intracellular fatty acid concentration. Whereas hyperglycemia may augment the reesterification process, it does not appear to be necessary for an increased rate of reesterification during epinephrine infusion. 
The direct effect of epinephrine on both lipolysis and reesterification is supported by a recent study we performed in severely burned patients in whom plasma epinephrine concentration was significantly elevated (9). In the basal state, these patients had elevated rates of lipolysis and of TG/FA cycling (fivefold elevation). When they were given beta adrenergic blockade, the rate of lipolysis was reduced significantly, as was the rate of TG/FA cycling, yet there was minimal effect on plasma glucose concentration, glucose production, or glucose cycling (9).

We had anticipated both a direct effect of glucocorticoid treatment on substrate cycling as well as an interactive effect of glucocorticoids with both glucagon and epinephrine. The primary basis for this expectation was a study by Issekutz in conscious dogs (6). Issekutz observed an eightfold increase in glucose cycling with methylprednisolone treatment alone, and a significant amplification of the stimulatory effect of glucagon on substrate cycling when it was given after methylprednisolone treatment. In contrast to the finding of Issekutz (6), we observed no effect of prednisone treatment alone on either glucose or TG/FA cycling. Our observation is consistent with the results of other investigators who found no effect of cortisol infusion on total glucose production in both dogs (33) and man (34). Furthermore, rather than a synergistic effect with glucagon, we found that prednisone treatment blunted the response of glucose kinetics to glucagon infusion (Table I). Owing to the inhibitory effect of insulin on glucose cycling, it seems likely that the insulin response to the prednisone treatment counteracted any direct effect of prednisone on glucose cycling. Furthermore, this insulin response to prednisone was apparently pronounced enough to also block the normal stimulatory effect of glucagon. This explanation could only be proven by repeating the studies involving prednisone treatment while simultaneously inhibiting the insulin response.

Whereas the prednisone treatment blunted the response of glucose cycling to glucagon, it did not affect the stimulation of TG/FA cycling by epinephrine (Fig. $10 \mathrm{~B}$ and Table II). This is consistent with our conclusion cited above that epinephrine works directly to stimulate TG/FA cycling, rather than being dependent on changes in glucose and/or insulin concentration to stimulate reesterification. The insulin concentration during epinephrine infusion was much higher after prednisone treatment than before, yet the response of both $R_{\mathrm{a}}$ glycerol and $\boldsymbol{R}_{\mathrm{a}}$ FFA were almost exactly the same on each study day (Fig. 10, $A$ and $B$ ).

We have attempted to elucidate the role of hyperglycemia, per se, in the control of substrate cycling, because the hormone treatments tested caused the blood glucose concentration to increase significantly. We observed no significant effect of hyperglycemia on glucose cycling, which is consistent with the recent report of Bell et al. (10). As reported in the dog (35), hyperglycemia had an inhibitory effect on lipolysis and a corresponding effect on FFA mobilization. In contrast, we have previously observed that when glucose is infused and insulin is allowed to increase, reesterification is stimulated more than lipolysis is inhibited, so that TG/FA cycling increases (15). By deduction, it appears insulin is necessary for hyperglycemia to effectively increase reesterification.

One of the major physiological roles of substrate cycles has been proposed to be their contribution to overall energy expenditure. Since ATP is hydrolyzed with each revolution of a cycle, but there is no net conversion of substrate to product, there is an increase in thermogenesis and energy expenditure (1). As explained above, in this study we were not able to relate the observed changes in substrate cycling with directly measured rates of energy expenditure. Nonetheless, the changes in substrate cycling that we observed are consistent with other experiments assessing the role of hormones on metabolic rate. It has recently been shown that glucagon stimulates metabolic rate in normal volunteers and that this effect is counteracted by insulin (36). Our data indicate that increased glucose cycling may be a biochemical basis for a glucagon-induced increase in energy expenditure. Similarly, it seems likely that sympathetic nervous system stimulation increases metabolic rate in man (37). Our data suggest that increased TG/FA cycling may contribute to this response.

Since, by definition, the existence of substrate cycles results in increased energy expenditure without any change in either the amount of substrate or product, the physiological significance of these cycles has been debated. One perspective is that these "futile" cycles serve no purpose beyond thermogenesis (2). Alternatively, Newsholme and Crabtree (1) have demonstrated that substrate cycling can provide a mechanism of variable sensitivity for the control of flux. They have shown theoretically that cycling will amplify the control of flux to a given change in regulator (e.g., hormone) concentration by $1+C / J$, where $C$ is the rate of cycling and $J$ is the rate of flux. Although this calculation may not be strictly applicable to the in vivo situation, it nonetheless is useful in addressing the issue of whether metabolic cycling is futile, or if it serves an important role in metabolic regulation. Inspection of the data from the TG/FA data in our study reveals that sensitivity was amplified by stimulation of cycling by epinephrine. Epinephrine infusion increased $1+C / J$ from 1.06 to 1.37 when given alone, and from 1.07 to 1.51 when infused after prednisone treatment. The $30-50 \%$ amplification of sensitivity of control of FFA flux by TG/FA cycling induced by epinephrine is consistent with the fact that severely burned patients given propranolol had a reduction in $1+C / J$ (for TG/FA cycling and FFA flux) from 1.84 to 1.39 (9). The finding that epinephrine increases the sensitivity of control of the rate of release of FFA by means of stimulating TG/FA cycling in humans is consistent with studies done in animals (7), and confirms the importance of this substrate cycle in the regulation of metabolism. In contrast, the marked stimulation of glucose cycling by glucagon was not accompanied by a concomitant increase in $1+C / J$. Although $1+C / J$ increased after glucagon by $8-12 \%$ (average over $1 \mathrm{~h}$ ) in each group, this is a small amount when compared with the magnitude of increase in cycling rate (from 150 to $300 \%$ ). Furthermore, it has been pointed out that increased glucose cycling contributes to the lack of glycemic control after glucose infusions in type II diabetes (13), and since glucose cycling is elevated in burned patients (9), it is likely that the hyperglycemia that results during glucose infusions in those patients is also in part the consequence of increased glucose cycling. Thus, it may be a mistake to generalize as to whether substrate cycling in humans is futile, or if it plays an important role in amplifying the enzymatic control of substrate flux. Clearly, changes in TG/FA cycling can modify control of FFA flux, but it is uncertain if there are conditions in which stimulation of the glucose cycle would result in an amplification of metabolic control of hepatic glucose output. 


\section{Acknowledgments}

The authors wish to acknowledge the help of the nursing staff of the Clinical Research Center in performing the infusions. Excellent technical assistance was provided by Susan Fons, Esther Surriga, and Nitina Sehgal, and we thank Judy Chadwick for the typing and preparation of the manuscript.

This work was supported by National Institutes of Health grant DK-34817 and GCRC grant 00073 , and by a grant from the Shriners Hospitals of North America.

\section{References}

1. Newsholme, E. A., and B. Crabtree. 1976. Substrate cycles in metabolic regulation and in heat generation. Biochem. Soc. Symp. 41:61-109.

2. Katz, J., and R. Rognstad. 1976. Futile cycles in the metabolism of glucose. Curr. Top. Cell. Regul. 10:237-289.

3. Hue, L. 1981. The role of futile cycles in the regulation of carbohydrate metabolism in the liver. Adv. Enzymol. 52:247-331.

4. Clark, D. G., R. Rognstad, and J. Katz. 1973. Isotopic evidence for futile cycles in liver cells. Biochem. Biophys. Res. Commun. 54:1141-1148.

5. Dunn, A., J. Katz, S. Golden, and M. Chenoweth. 1976. Estimation of glucose turnover and recycling in rabbits using various $\left[{ }^{3} \mathrm{H}\right.$, $\left.{ }^{14} \mathrm{C}\right]$-glucose labels. Am. J. Physiol. 230:1159-1162.

6. Issekutz, B., Jr. 1977. Studies on hepatic glucose cycles in normal and methylprednisolone-treated dogs. Metab. Clin. Exp. 26:157-170.

7. Brooks, B. J., J. R. S. Arch, and E. A. Newsholme. 1983. Effect of some hormones on the rate of the triacylglycerol/fatty-acid substrate cycle in adipose tissue of the mouse in vivo. Biosci. Rep. 3:263-267.

8. Shulman, G. I., P. W. Ladenson, M. H. Wolfe, E. C. Ridgway, and R. R. Wolfe. 1985. Substrate cycling between gluconeogenesis and glycolysis in euthyroid, hypothyroid, and hyperthyroid man. J. Clin. Invest. 76:757-764.

9. Wolfe, R. R., D. N. Herndon, F. Jahoor, H. Miyoshi, and M. H. Wolfe. 1987. Effect of severe burn injury on substrate cycling by glucose and fatty acids. N. Engl. J. Med. 317:403-408.

10. Bell, P. M., R. G. Firth, and R. A. Rizza. 1986. Effects of hyperglycemia on glucose production and utilization in humans. Measurement with $\left[2^{3} \mathrm{H}\right]-,\left[3^{3} \mathrm{H}\right]-$, and $\left[6^{14} \mathrm{C}\right]$ glucose. Diabetes. $35: 642-$ 648.

11. Karlander, S., A. Roovete, M. Vranic, and S. Efendic. 1986. Glucose and fructose 6-phosphate cycle in humans. Am. J. Physiol. 251:E530-E536.

12. Karlander, S., M. Vranic, and S. Efendic. 1986. Increased glucose turnover and glucose cycling in acromegalic patients with normal glucose tolerance. Diabetologia. 29:778-783.

13. Efendic, S., S. Karlander, and M. Vranic. 1987. Mild type II diabetes markedly increases glucose cycling in the postabsorptive state and during glucose infusions irrespective of obesity. Diabetes. 36:4A.

14. Efendic, S., A. Wajngot, and M. Vranic. 1985. Increased activity of the glucose cycle in the liver: early characteristic of type 2 diabetes. Proc. Natl. Acad. Sci. USA. 82:2965-2969.

15. Wolfe, R. R., and E. J. Peters. 1987. Lipolytic response to glucose infusion in human subjects. Am. J. Physiol. 252:E218-E223.

16. Vaughan, G. M., R. A. Becker, R. H. Unger, M. G. Ziegler, T. M. Siler-Khodr, B. A. Pruitt, Jr., and A. D. Mason, Jr. 1985. Nonthyroidal control of metabolism after burn injury: possible role of glucagon. Metab. Clin. Exp. 34:637-641.

17. Heckemeyer, C. M., J. Barker, W. C. Duckworth, and S. S. Solomon. 1983. Studies of the biological effect and degradation of glucagon in the rat perifused isolated adipose cell. Endocrinology. 113:270-276.
18. Chatzipanteli, K., and D. Saggerson. 1983. Streptozotocin diabetes results in increased responsiveness of adipocyte lipolysis to glucagon. FEBS (Fed. Eur. Biochem. Soc.) Lett. 155:135-138.

19. McGuire, E. A. H., J. H. Helderman, J. D. Tobin, R. Andres, and M. Berman. 1976. Effects of arterial versus venous sampling on analysis of glucose kinetics in man. J. Appl. Physiol. 41:565-573.

20. Wolfe, R. R., J. E. Evans, C. J. Mullany, and J. F. Burke. 1980. Measurement of plasma free fatty acid turnover and oxidation using $\left[1-{ }^{13} \mathrm{C}\right]$-palmitic acid. Biomed. Mass Spectrom. 7:168-171.

21. Clutter, W. E., D. M. Bier, S. D. Shah, and P. E. Cryer. 1980. Epinephrine plasma metabolic clearance rates and physiologic thresholds for metabolic and hemodynamic actions in man. J. Clin. Invest. 66:94-101.

22. Hussain, M. N., and C. R. Benedict. 1985. Radioenzymatic microassay for simultaneous estimations of dopamine, norepinephrine, and epinephrine in plasma, urine and tissues. Clin. Chem. 31:1861-1864.

23. Wolfe, R. R. 1984. Tracers in Metabolic Research: Radioisotope and Stable Isotope/Mass Spectrometry Methods. Alan R. Liss, New York. 262-263.

24. Rosenblatt, J., and R. R. Wolfe. 1988. Calculation of substrate flux using stable isotopes. Am. J. Physiol. In press.

25. Wegman, E. J., and W. Wright. 1985. Splines in statistics. $J$. Am. Stat. Assoc. 78:351-366.

26. Bortz, W. M., P. Paul, A. G. Hoff, and W. L. Holmes. 1972. Glycerol turnover and oxidation in man. J. Clin. Invest. 51:15371546.

27. Altszuler, N., A. Barkai, C. Bjerknes, G. Gottlieb, and R. Steele. 1975. Glucose turnover values in the dog obtained with various species of labeled glucose. Am. J. Physiol. 229:1662-1667.

28. Newgard, C. B., D. W. Foster, and J. D. McGarry. 1984. Evidence for suppression of glucose-6-phosphatase with carbohydrate feeding. Diabetes. 33:191-195.

29. Chenoweth, M., and A. Dunn. 1978. Fructose-6-phosphate substrate cycling and hormonal regulation of gluconeogenesis in vivo. Am. J. Physiol. 235:E295-E303.

30. Spence, J. T., and H. C. Pitot. 1980. Maintenance of glucokinase activity in primary hepatocyte cultures. J. Cell. Physiol. 103:173178.

31. Hue, H. 1980. The role of futile cycles in the regulation of carbohydrate metabolism in the live. Adv. Enzymol. 52:247-331.

32. Rizza, R. A., L. A. Mandarino, and J. E. Gerich. 1982. Effects of growth hormone on insulin action in man. Mechanism of insulin resistance, impaired suppression of glucose production, and impaired stimulation of glucose utilization. Diabetes. 31:663-669.

33. Challiss, R. A. J., J. R. S. Arch, B. Crabtree, and E. A. Newsholme. 1984. Measurement of the rate of substrate cycling between fructose 6-phosphate and fructose 1, 6-bisphosphate in skeletal muscle by using a single-isotope technique. Biochem. J. 223:849-853.

34. Eigler, N., L. Sacca, and R. S. Sherwin. 1979. Synergistic interactions of physiologic increments of glucagon, epinephrine, and cortisol in the dog. A model for stress-induced hyperglycemia. J. Clin. Invest. 63:114-123.

35. Shulman, G. I., P. E. Williams, J. E. Liljenquist, W. W. Lacy, U. Keller, and A. D. Cherrington. 1980. Effect of hyperglycemia independent of changes in insulin or glucagon on lipolysis in the conscious dog. Metab. Clin. Exp. 29:317-320.

36. Nair, K. S. 1987. Hyperglucagonemia increases resting metabolic rate in man during insulin deficiency. J. Clin. Endocrinol. Metab. 64:896-901.

37. Danforth, E., Jr., K. J. Acheson, L. Christin, E. Ravussin, R. L. Galeazzi, and E. Jequier. 1987. A role for the sympathetic nervous system in the regulation of resting and glucose/insulin stimulated thermogenesis in man. Clin. Res. 35:501 A. (Abstr.) 